\title{
Which One Is Better to Reduce the Infection Rate, Early or Late Cranioplasty?
}

\author{
Jae-Sang Oh, M.D., Kyeong-Seok Lee, M.D., Ph.D., Jai-Joon Shim, M.D., Ph.D., Seok-Mann Yoon, M.D., Ph.D., Jae-Won Doh, M.D., Ph.D., \\ Hack-Gun Bae, M.D., Ph.D. \\ Department of Neurosurgery, Soonchunhyang University Cheonan Hospital, Cheonan, Korea
}

\begin{abstract}
Objective : Decompressive craniectomy is an effective therapy to relieve high intracranial pressure after acute brain damage. However, the optimal timing for cranioplasty after decompression is still controversial. Many authors reported that early cranioplasty may contribute to improve the cerebral blood flow and brain metabolism. However, despite all the advantages, there always remains a concern that early cranioplasty may increase the chance of infection. The purpose of this retrospective study is to investigate whether the early cranioplasty increase the infection rate. We also evaluated the risk factors of infection following cranioplasty.

Methods : We retrospectively examined the results of 131 patients who underwent cranioplasty in our institution between January 2008 and June 2015. We divided them into early ( $\leq 90$ days) and late (>90 days after craniectomy) groups. We examined the risk factors of infection after cranioplasty. We analyzed the infection rate between two groups.

Results : There were more male patients (62\%) than female (38\%). The mean age was 49 years. Infection occurred in 17 patients (13\%) after cranioplasty. The infection rate of early cranioplasty was lower than that of late cranioplasty (7\% vs. 20\%; $p=0.02)$. Early cranioplasty, non-metal allograft materials, re-operation before cranioplasty and younger age were the significant factors in the infection rate after cranioplasty $(p<0.05)$. Especially allograft was a significant risk factor of infection (odds ratio, 12.4; 95\% confidence interval, 3.24-47.33; $p<0.01$ ). Younger age was also a significant risk factor of infection after cranioplasty by multivariable analysis (odds ratio, 0.96; 95\% confidence interval, 0.96-0.99; $p=0.02$ ).

Conclusion : Early cranioplasty did not increase the infection rate in this study. The use of non-metal allograft materials influenced a more important role in infection in cranioplasty. Actually, timing itself was not a significant risk factor in multivariate analysis. So the early cranioplasty may bring better outcomes in cognitive functions or wound without raising the infection rate.
\end{abstract}

Key Words : Cranioplasty · Infection · Decompressive craniectomy · Hydroxyapatities.

\section{INTRODUCTION}

Decompressive craniectomy is a method to relieve intracranial pressure (ICP) in various emergency situations like traumatic brain injury, ischemic and hemorrhagic strokes and brain edema in brain tumor ${ }^{2,3)}$. A large defect of cranial bone after decompressive craniectomy inhibits early rehabilitation process. It is associated with prolonged period of immobility, pulmonary infection and thromboembolic events. A cranioplasty for skull defect is helpful to protect against head trauma and prevention of low-pressure syndrome ${ }^{15,25,26)}$. Early bone flap replacement may improve the brain perfusion, cerebrospinal fluid dynamics, and cognitive function ${ }^{3,12,24)}$. However, one of the most challenging complications is infection in cranioplasty after decompressive craniectomy. Many authors reported that complication and morbidity rates after cranioplasty were from $10-40 \%{ }^{6,7,19)}$. Timing of cranioplasty can also affect the cognitive function as well as infection rate ${ }^{7,10)}$. Early cranioplasty has been associated with subdural and epidural fluid collections, seizure, recurrent brain edema, and hydrocephalus. On the other hand, some authors reported that delayed cranioplasty was also a risk factor of infection with allograft bone ${ }^{29)}$.

We investigated whether early surgery, defined as cranioplasty performed within 90 days, was associated with a lower rate of infection. We also analyzed several factors which might influence the infection rate after cranioplasty.

\section{MATERIALS AND METHODS}

From January 2008 to June 2015, we performed 131 cranioplas-

- Received : January 26, $2016 \cdot$ Revised : March 7, $2016 \cdot$ Accepted : April 3, 2016

- Address for reprints : Jae-Sang Oh, M.D.

Department of Neurosurgery, Soonchunhyang University Cheonan Hospital, 31 Suncheonhyang 6-gil, Dongnam-gu, Cheonan 31151, Korea

Tel : +82-41-570-3647, Fax : +82-41-572-9297, E-mail : metatron1324@naver.com

- This is an Open Access article distributed under the terms of the Creative Commons Attribution Non-Commercial License (http://creativecommons.org/licenses/by-nc/3.0) which permits unrestricted non-commercial use, distribution, and reproduction in any medium, provided the original work is properly cited. 
ty procedures on patients who had undergone decompressive craniectomy and had a follow-up period of at least 1 year after cranioplasty. We collected data on the age, sex, the cause of craniectomy, the presence of extraventricular drainage (EVD) or ventriculoperitoneal (VP) shunt before cranioplasty, the use of allograft bone, the number of bone pieces, the defected cranial bone size, reoperation before cranioplasty (for post-operative epidural hematoma), and post-operative epidural hematoma (EDH) after cranioplasty by retrospective chart reviews. The causes of craniectomy were divided according to initial diagnosis for craniectomy into the following groups : 1) traumatic brain injury, 2) non-traumatic brain injury (ischemic or hemorrhagic stroke, subarachnoid hemorrhage due to aneurysm rupture). The number of bone pieces had distribution from 1 to 2 or more pieces, and during all cranioplasty procedures miniplates were used for assembly and fixation. The size of removed cranial bone flaps was also divided as follows; 1$)$ small bone flap $(\leq 10 \times 10 \mathrm{~cm})$, 2) Large ( $>10 \times 10 \mathrm{~cm}$ or bifrontal ). Exclusion criteria were; 1$)$ cranioplasty materials used the metallic form, 2) other cause of craniectomy; such as brain tumor, infection, 3) patients who were treated in other hospitals. Decompressive craniectomy was performed for high ICP control, despite medical management in acute phase. And the removed cranial bone flaps were immediately frozen and stored under sterile conditions at $-80^{\circ} \mathrm{C}$. We tried to use the autograft for cranioplasty on most patients, but allograft was substituted for dirty or infected bone at craniectomy or large defect cranial bone pieces on some patients. Only polymethyl methacrylate (PMMA) or mixed with PMMA and hydroxyapatite (HA) were commonly used for non-metal allograft cranioplasty. In trauma, if they had a dirty or open wound, irrigation with normal saline was performed actively before decompressive craniectomy. We used allograft materials with PMMA in usual, and coated HA on some bone defect or gap. After cranioplasty, infection was defined the skin problems on postoperative findings, C-reactive protein, or the abnormal enhanced fluid collection on post-operative enhanced computed tomography (CT). And almost all infected graft bone flaps were totally removed as soon as diagnosis of infection was made after cranioplasty.

\section{Timing of cranioplasty}

We compared patient groups who had cranioplasty early $(\leq 90$ days after craniectomy), with those who had it late ( $>90$ days). The timing of cranioplasty was decided according to surgeon's preference or the condition of patients.

\section{Data analysis}

Quantitative variables are expressed as mean \pm SD. We used $\chi^{2}$ analysis to test associations between categorical variables and $t$ test for continuous variables.

The risk of infection associated with cranioplasty was evaluated by univariate analysis. And then only variables with values of $p<0.10$ in the univariate analysis were included in the multiple logistic regression. Values of $p<0.05$ were considered statisti- cally significant. The odds ratio (OR) and 95\% confidence interval (CI) were determined in the logistic regression analysis. Commercially available software (SPSS version 14, IBM Corp., Armonk, NY, USA) was used for all statistical analysis.

\section{RESULTS}

\section{Patient characteristics and cranioplasty groups}

The median age of this study population was 49 years (range 3 to 79 ). Women constituted $38 \%$ of them. The causes of decompressive craniectomy were traumatic ICH in 53 patients (40\%), spontaneous ICH or infarction in 58 patients (44\%), and subarachnoid hemorrhage with ruptured aneurysm in 20 patients (16\%) (Table 1). Overall infection rate was $13 \%$.

\section{Age and sex}

The mean age of the Infection group was younger than the no-infection group $(p<0.01)$. And sex was not a significant difference between two groups $(p=0.18)$.

\section{Timing of cranioplasty}

In overall data, the median time-to-cranioplasty was 142 days (range 18 to 917). As 85 (62\%) patients were followed-up by our department, the median follow-up period was 546 days, the minimum was less than 1 year, and the maximum was 6 years.

The time intervals between craniectomy and cranioplasty ranged diversely from 18 days to 917 days, depending on several factors such as the age and condition of the patient, skin flap concavity, the cause of craniectomy and preference of surgeon. We analysed factors on which surgeons had determined the early cranioplasty by logistic regression analysis. The reoperation before cranioplasty was associated with late cranioplasty (OR, 3.1; 95\% CI, 1.3 to $7.6, p=0.09$ ). Besides, there was no significant difference in age, and the cause of craniectomy between early and late cranioplasty $(p>0.05)$ (Table 1$)$.

\section{Infection of early vs. late cranioplasty}

Seventeen (13\%) had a post-cranioplasty infection. The infection rate of early cranioplasty was lower than the infection rate of late cranioplasty ( $7 \%$ vs. $20 \%$; $p=0.02$ ) (Table 2 ). And early cranioplasty is significant related with infection after cranioplasty on unadjusted odd ratio ( $p=0.03$, OR $3.42,95 \%$ CI $1.13-10.36$ ).

\section{Infection rate according to history of craniectomy}

Fifty-three patients had craniectomy performed due to trauma. Of these, 45 patients were in the no-infection group and 8 patients were in the infection group. 8 (15\%) of 53 trauma patients had infection after cranioplasty. But the history of craniectomy before cranioplasty was not associated with the higher rates of infection after cranioplasty $(p=0.50)$.

\section{Use of artificial bond graft (non-metal)}

Nineteen (15\%) patients had the artificial bone graft per- 
Table 1. Characteristics of early ( $<90$ days) and late ( $>90$ days) group of cranioplasty

\begin{tabular}{|c|c|c|c|}
\hline Variables & Early (<90 days) & Late ( $>90$ days) & $p$-value \\
\hline No. of patients & 72 & 59 & \\
\hline Age in years, median (SD) & $48 \pm 17$ & $50 \pm 16$ & 0.57 \\
\hline Sex (male), n (\%) & $44(61)$ & $37(63)$ & 0.85 \\
\hline Timing of CP in days, median (SD) & $58( \pm 18)$ & $244( \pm 190)$ & $<0.01^{\star}$ \\
\hline Hypertension, n (\%) & $22(31)$ & $28(47)$ & $0.04^{*}$ \\
\hline $\mathrm{DM}, \mathrm{n}(\%)$ & $5(7)$ & $7(12)$ & 0.33 \\
\hline Cause of craniectomy & & & 0.17 \\
\hline Trauma & 33 & 20 & \\
\hline Non-trauma (stroke) & 39 & 39 & \\
\hline EVD or shunt before $\mathrm{CP}$ & $16(22)$ & $11(19)$ & 0.61 \\
\hline Graft for $\mathrm{CP}$ & & & 0.08 \\
\hline Autograft & 65 & 47 & \\
\hline Allograft & 7 & 12 & \\
\hline Bone pieces & & & 0.09 \\
\hline$\leq 1$ pieces & 60 & 51 & \\
\hline$\geq 2$ pieces & 12 & 8 & \\
\hline Bone size & & & 0.86 \\
\hline Small & 51 & 41 & \\
\hline Large & 21 & 18 & \\
\hline Re-op before $\mathrm{CP}$ & $10(14)$ & $19(32)$ & $0.01^{*}$ \\
\hline Post-op EDH after CP & $4(6)$ & $7(12)$ & 0.19 \\
\hline Infection & $5(7)$ & $12(20)$ & $0.02^{*}$ \\
\hline
\end{tabular}

${ }^{\star} p<0.05$. CP : cranioplasty, DM : diabetes mellitus, EVD : extraventricular drainage, EDH : epidural hematoma

Table 2. Univariate analysis comparing the no-infection and the infection groups after cranioplasty

\begin{tabular}{|c|c|c|c|}
\hline Variables & No infection & Infection & $p$-value \\
\hline No. of patients & 114 & 17 & \\
\hline Age in years, median (SD) & $50( \pm 16)$ & $39( \pm 15)$ & $<0.01^{*}$ \\
\hline Sex (male), n (\%) & $68(60)$ & $13(76)$ & 0.18 \\
\hline Timing of CP in days, median (SD) & $113( \pm 98)$ & $337( \pm 296)$ & $<0.01^{*}$ \\
\hline Early ( $\leq 90$ days), $\mathrm{n}(\%)$ & $67(59)$ & $5(29)$ & $0.02^{*}$ \\
\hline Late (>90 days), n (\%) & $47(41)$ & $12(71)$ & \\
\hline Hypertension, n (\%) & $71(62)$ & $10(59)$ & 0.78 \\
\hline $\mathrm{DM}, \mathrm{n}(\%)$ & $5(8)$ & $7(82)$ & 0.19 \\
\hline Cause of craniectomy & & & 0.55 \\
\hline Trauma & 45 & 8 & \\
\hline Non-trauma (stroke) & 69 & 9 & \\
\hline EVD or shunt before CP & $25(22)$ & $11(12)$ & 0.33 \\
\hline Graft for CP & & & $<0.01^{*}$ \\
\hline Autograft & 105 & 7 & \\
\hline Allograft & 9 & 10 & \\
\hline Bone pieces & & & 0.77 \\
\hline$\leq 1$ pieces & 97 & 14 & \\
\hline$\geq 2$ pieces & 17 & 3 & \\
\hline Bone size & & & 0.97 \\
\hline Small & 80 & 12 & \\
\hline Large & 34 & 5 & \\
\hline Re-op before CP, n (\%) & $20(18)$ & $9(53)$ & $0.01^{*}$ \\
\hline Post-op EDH after CP, n (\%) & $9(8)$ & $2(12)$ & 0.59 \\
\hline
\end{tabular}

${ }^{\star} p<0.05$. CP : cranioplasty, DM : diabetes mellitus, EVD : extraventricular drainage, EDH : epidural hematoma 
formed for cranioplasty. Non-metal allograft cranioplasty were performed using PMMA or HA [only PMMA 13 (68\%); mixed PMMA+HA 6 (32\%)]. Of these, 10 patients had infection after cranioplasty. The use of artificial bone graft was associated with infection after cranioplasty $(p=0.00)$.

\section{Multiple bone pieces}

Multiple bone pieces were not associated with the higher rates of infection after cranioplasty $(p=0.61)$.

\section{Bone size of craniectomy}

Ninety-two (70\%) patients had small craniectomy performed for decompression and 12 patients had infection after cranioplasty. And 12 (9\%) patients underwent the wide bifrontal craniectomy. But bone size of craniectomy was not associated with infection after cranioplasty $(p=0.61)$.

\section{Reoperation before cranioplasty}

After craniectomy, 29 (22\%) patients underwent reoperation due to postoperative epidural hematoma, progressively increasing ICH or brain swelling after decompressive craniectomy. Of these, 9 patients had infection after cranioplasty. Multiple reoperations before cranioplasty were associated with infection after cranioplasty $(p=0.00)$.

\section{Post-operative EDH after cranioplasty}

Eleven (8\%) patients had the post-operative epidural hematoma on post-operative CT. Two patients had infection after cranioplasty compared with 16 (13\%) of non-EDH groups. Postoperative EDH after cranioplasty was not associated with infection $(p=0.59)$ (Table 2).

\section{Risk factors of infection after cranioplasty}

We performed a multivariate logistic regression analysis of those variables $(p<0.10)$ significantly associated with infection after cranioplasty. Multivariate analyses indicated that the infection after cranioplasty was independently associated with the

Table 3. Unadjusted odd ratio of infection according to timing of cranioplasty after cranioplasty

\begin{tabular}{lccc}
\multicolumn{1}{c}{ Variables } & OR & $95 \%$ CI & $p$-value \\
\hline Timing of CP & 3.42 & 1.13 to 10.36 & 0.03 \\
Early ( $\leq 90$ days) & & & \\
Late (>90 days) & & & \\
\hline CP : cranioplasty & & &
\end{tabular}

Table 4. Adjusted odds ratio for risk factors of infection after cranioplasty

\begin{tabular}{lllc}
\hline \multicolumn{1}{c}{ Variables } & OR & \multicolumn{1}{c}{$95 \%$ CI } & $p$-value \\
\hline Allograft & 12.4 & 3.24 to 47.33 & $<0.01^{*}$ \\
Age & 0.96 & 0.92 to 0.99 & 0.027 \\
Timing of CP & 2.61 & 0.67 to 10.20 & 0.17 \\
Re-op before CP & 1.77 & 0.43 to 7.28 & 0.43 \\
\hline
\end{tabular}

${ }^{*} p<0.05$ for statistical significance. $\mathrm{CP}$ : cranioplasty use of allograft ( $p<0.01$, adjusted OR 12.4, 95\% CI 3.24-47.33) and age ( $p=0.02$, adjusted OR $0.96,95 \%$ CI $0.92-0.99$ ). But late cranioplasty and re-operation before cranioplasty were not associated with infection rate $(p>0.05)$ (Table 4$)$.

\section{DISCUSSION}

Cranioplasty after decompressive craniectomy is an important procedure for controlling the increased ICP as well as safety and cosmetics of patients. Recent reports have suggested cranioplasty may help improve neurological status, both physiologically and clinically ${ }^{3,49)}$. Although postoperative complication rates vary widely, there is no substitute for specific materials and technique for cranioplasty ${ }^{6,719)}$. Early cranioplasty has the benefit of improving cognitive function and levels of consciousness because decreased cerebral blood flow and disturbed brain metabolism could be restored ${ }^{20,27)}$.

Many investigators reported that early cranioplasty is associated with increasing morbidity and complication because of interruption of wound healing and the performance of a second procedure on just recovering from initial insult, and possibility of leakage of cerebrospinal fluid. However, recent studies reported that early cranioplasty may prevent complications from a sunken scalp, and changes in brain perfusion or abnormal cerebrospinal fluid hydrodynamics from occurring for a protracted period ${ }^{12,24,28)}$. Chang et al. ${ }^{7)}$ study found a significantly lower rate of infection in patients undergoing early ( $\leq 3$ months) cranioplasty compared with those undergoing cranioplasty after 3 months ( $9 \%$ vs. $26 \%$; $p=0.007$ ). And other studies showed the similar results ${ }^{23)}$. The delayed cranioplasty means that the average bone preservation period is longer than that of early cranioplasty. As the preserving period for autograft bone flap is longer, the chance of flap contamination is increased ${ }^{17,23}$. Some authors assert that flaps stored beyond 10 months should be resterilized or discarded ${ }^{17)}$. There are so many methods for preventing the infection after $\mathrm{CP}$, such as bone flap could be sealed in three sterilized vinyl bags and stored at $-35^{\circ} \mathrm{C}$ or $-84^{\circ} \mathrm{C}$ or preserved between the abdominal fat and muscle ${ }^{1)}$. As for our population, we also sealed bone flap in a deep-freezer and we found a significantly lower rate of infection on early cranioplasty ( $7 \%$ vs. $20 \%$, $p=0.02$ ).

In our study, most patients who experienced wound complication as defined by infection and wound dehiscence, required reoperation. Some patients had the infection with a symptom of high fever and highly enhanced epidural or subdural abscess without wound dehiscence. All dehiscence of wounds were immediately repaired, and as high CRP or enhanced CT findings were developed, these patients were subsequently treated with intravenous antibiotics (vancomycine or ceftriaxone). If high CRP and fever was sustained despite administration of intravenous antibiotics, wound revision and removal of bone flap were performed. The clinical course of infected patients after cranioplasty was generall favorable and there was no mortality at 3 
months because of immediate surgical intervention.

A patient's own cranial bone flap is regarded as the material of first choice of cranioplasty. On our study, allograft was also significantly associated with increasing the infection rate of cranioplasty $(p<0.001)$. If the bone flap is lost due to osteolysis or infection, we chose the allograft materials instead of autograft bone. We usually performed non-metal cranioplasty using PMMA, but HA were used with it on some bony gap or defect. It is well-known that the materials most frequently used for cranioplasty are PMMA, HA, and titanium. Both PMMA and HA materials are most frequently used and still regarded as good choices for non-metal cranioplasty, because they have good biocompatibility and low $\operatorname{costs}^{21,22)}$. However, slow intraoperative modeling and incongruence in modeling for a large skull defect are disadvantages of these allograft materials. Some authors reported that allograft cranioplasty using PMMA and HA showed a higher rate of infection than autograft cranioplasty, and HA especially was regarded as contraindication of craniofacial reconstruction and pediatric population ${ }^{8,13,22,24)}$. The titanium plates give a good choice for cranioplasty based on low infection rate, their strength, biocompatibility, and suitability for postoperative imaging technique ${ }^{8,18}$. However, their cost is not only very high ranging from more than $\$ 2650$ in South Korea to $\$ 7000$ in other countries ${ }^{11)}$. Recently, newer synthetic materials have been found to have potential benefits such as nonreabsorbability and good cosmetic results. Moreover, the current analysis showed the infection rate between autograft and allograft were not significantly different ${ }^{29)}$.

On trauma of etiology, complex traumatic brain injury with penetrating injuries, complex fracture, dirty wound, and frontal sinus involvement is related with higher complication after cranioplasty. Especially on complex traumatic injury, cranioplasty with acrylic flap had the higher infection rate although ${ }^{19)}$. On our study, initially etiology were classified with trauma, stroke (intracerebral hemorrhage and cerebral infarction), and subarachnoid hemorrhage [53 (40\%); 58 (44\%); 20 (16\%)], but each etiology were not related with infection rate after cranioplasty.

Some reported that frontal cranioplasty was significantly more likely to have complications. Several factors may have contributed to this fact, including longer incision for bifrontal defect, less available temporalis muscle to provide soft tissue coverage, exposure of frontal sinus, and longer operative time ${ }^{5,22}$. Total 12 cases of bifrontal cranioplasty were involved in our study, but there was no infection in these cases. It is because if we had to expose the frontal sinus on initial operation, prefrontal pericranium was always used to completely cover the frontal sinus during initial operation without using the artificial bone source or other materials. There is debate as to whether the frontal sinus reconstruction with artificial bone may increase the infection rate of cranioplasty or not. And we think that these issues require further study.

Risk factors for general postoperative neurological infections include altered sensoria, multiple operations, preexisting infec- tion, emergency operation, long duration of operation, cerebrospinal fluid leakage, and poor neurological outcome ${ }^{16)}$. On our study, the factor associated with infection after cranioplasty included younger age, early ( $\leq 90$ days) operation, use of nonmetal allograft, and re-operation before cranioplasty by univariate analysis $(p<0.05)$. On multivariable analysis, non-metal allograft is a significant risk factor of infection after cranioplasty (odd ratio, 12.4; 95\% confidence interval, 3.24-47.33; $p<0.01$ ). And younger age was also a significant factor of infection after cranioplasty by multivariate analysis (odds ratio, 0.96 ; $95 \%$ confidence interval, $0.96-0.99 ; p=0.02$ ). Timing of cranioplasty was not a risk factor of infection after cranioplasty on our study $(p=0.17)$ (Table 3$)$. In our study, young age $(<40)$ group had the more common history of trauma and higher incidence of reoperation before cranioplasty. On trauma mechanism, younger age had higher incidence of traffic accident and multiple organ damages ${ }^{14)}$. Decompressive craniectomy in traumatic brain injury can increase reoperation rates because it already have the some coagulopathy and contusion of galea and muscle. Young age groups tended to have a low consciousness level initially and a poor modified Rankin scale, despite high mortality of elderly patients. Although it seems to be a selection bias, it is wellknown that decompressive craniectomy is mainly performed on traumatic brain injury.

There are several limitations in this study. First, this is not a randomized trial. Our cranioplasty was performed by 3 neurosurgeons and timing of cranioplasty was decided by each. Some patients who were bedridden or in a vegetative state, cranioplasty was postponed by several years, because of follow-up loss or rehabilitation. We thought these patients on delayed cranioplasty should be included in the study to maintain the accuracy of the infection rate. As some patients who had delayed cranioplasty were in relatively poor state, it may contribute to the low infection rate in early cranioplasty. However, most patients who performed the decompressive craniectomy had poor consciousness because of high ICP. Second, this study was the single center retrospective design and relatively sample size, so it was difficult to control for known and unknown bias impossible. However, in general, cranioplasty itself already had some bias, for example, some different indication of decompressive craniectomy for each surgeon and lateralization to trauma in our country. Although some selection bias was occurred, this data and result is enough to support the hypothesis that timing of cranioplasty have no effect to infection rate as univariate analysis revealed a clear statistical association. Furthermore, this study needs to exam prospectively in a uniform population employing uniform techniques and uniform protocol.

\section{CONCLUSION}

It is known that early cranioplasty may contribute to better neurological outcomes. Infection of cranioplasty is a big problem and its incidence is not low. Many neurosurgeons hesitate 
to do cranioplasty early, because of the chance of increasing the infection rate. In this study, early cranioplasty did not raise the infection rate. Rather than the timing of cranioplasty, the use of non-metal allograft materials was proved to be a more important risk factor for infection in cranioplasty. So early cranioplasty may result advantages and better outcomes in the cognitive function or wound without raising the infection rate after cranioplasty.

\section{References}

1. Açikgöz B, Ozcan OE, Erbengi A, Bertan V, Ruacan S, Açikgöz HG : Histopathologic and microdensitometric analysis of craniotomy bone flaps preserved between abdominal fat and muscle. Surg Neurol 26 : 557-561, 1986

2. Adamo MA, Deshaies EM : Emergency decompressive craniectomy for fulminating infectious encephalitis. J Neurosurg 108 : 174-176, 2008

3. Agner C, Dujovny M, Gaviria M : Neurocognitive assessment before and after cranioplasty. Acta Neurochir (Wien) 144 : 1033-1040; discussion 1040, 2002

4. Bijlenga P, Zumofen D, Yilmaz H, Creisson E, de Tribolet N : Orthostatic mesodiencephalic dysfunction after decompressive craniectomy. J Neurol Neurosurg Psychiatry 78 : 430-433, 2007

5. Blum KS, Schneider SJ, Rosenthal AD : Methyl methacrylate cranioplasty in children : long-term results. Pediatr Neurosurg 26 : 33-35, 1997

6. Broughton E, Pobereskin L, Whitfield PC : Seven years of cranioplasty in a regional neurosurgical centre. Br J Neurosurg 28 : 34-39, 2014

7. Chang V, Hartzfeld P, Langlois M, Mahmood A, Seyfried D : Outcomes of cranial repair after craniectomy. J Neurosurg 112 : 1120-1124, 2010

8. Costantino PD, Chaplin JM, Wolpoe ME, Catalano PJ, Sen C, Bederson JB, et al. : Applications of fast-setting hydroxyapatite cement : cranioplasty. Otolaryngol Head Neck Surg 123 : 409-412, 2000

9. Dujovny M, Fernandez P, Alperin N, Betz W, Misra M, Mafee M : Postcranioplasty cerebrospinal fluid hydrodynamic changes : magnetic resonance imaging quantitative analysis. Neurol Res $19: 311-316,1997$

10. Erman T, Demirhindi H, Göçer AI, Tuna M, Ildan F, Boyar B : Risk factors for surgical site infections in neurosurgery patients with antibiotic prophylaxis. Surg Neurol 63 : 107-112; discussion 112-113, 2005

11. Eufinger $H$, Wehmöller $M$ : Individual prefabricated titanium implants in reconstructive craniofacial surgery : clinical and technical aspects of the first 22 cases. Plast Reconstr Surg 102 : 300-308, 1998

12. Fodstad H, Love JA, Ekstedt J, Fridén H, Liliequist B : Effect of cranioplasty on cerebrospinal fluid hydrodynamics in patients with the syndrome of the trephined. Acta Neurochir (Wien) $70: 21-30,1984$

13. Friedman CD, Costantino PD, Synderman CH, Chow LC, Takagi S : Reconstruction of the frontal sinus and frontofacial skeleton with hydroxyapatite cement. Arch Facial Plast Surg 2 : 124-129, 2000

14. Fu TS, Jing R, McFaull SR, Cusimano MD : Recent trends in hospital- ization and in-hospital mortality associated with traumatic brain injury in Canada : a nationwide, population-based study. J Trauma Acute Care Surg 79 : 449-454, 2015

15. Gladstone HB, McDermott MW, Cooke DD : Implants for cranioplasty. Otolaryngol Clin North Am 28 : 381-400, 1995

16. Im SH, Jang DK, Han YM, Kim JT, Chung DS, Park YS : Long-term incidence and predicting factors of cranioplasty infection after decompressive craniectomy. J Korean Neurosurg Soc 52 : 396-403, 2012

17. Jho DH, Neckrysh S, Hardman J, Charbel FT, Amin-Hanjani S : Ethylene oxide gas sterilization : a simple technique for storing explanted skull bone. Technical note. J Neurosurg 107 : 440-445, 2007

18. Joffe J, Harris M, Kahugu F, Nicoll S, Linney A, Richards R: A prospective study of computer-aided design and manufacture of titanium plate for cranioplasty and its clinical outcome. Br J Neurosurg 13 : 576-580, 1999

19. Klinger DR, Madden C, Beshay J, White J, Gambrell K, Rickert K : Autologous and acrylic cranioplast : a review of 10 years and 258 cases. World Neurosurg 82 : e525-e530, 2014

20. Liang W, Xiaofeng Y, Weiguo L, Gang S, Xuesheng Z, Fei C, et al. : Cranioplasty of large cranial defect at an early stage after decompressive craniectomy performed for severe head trauma. J Craniofac Surg 18 : 526-532, 2007

21. Maas CS, Merwin GE, Wilson J, Frey MD, Maves MD : Comparison of biomaterials for facial bone augmentation. Arch Otolaryngol Head Neck Surg 116 : 551-556, 1990

22. Marchac D, Greensmith A : Long-term experience with methylmethacrylate cranioplasty in craniofacial surgery. J Plast Reconstr Aesthet Surg 61 : 744-752; discussion 753, 2008

23. Matsuno A, Tanaka H, Iwamuro H, Takanashi S, Miyawaki S, Nakashima M, et al. : Analyses of the factors influencing bone graft infection after delayed cranioplasty. Acta Neurochir (Wien) 148 : 535-540; discussion 540, 2006

24. Moreira-Gonzalez A, Jackson IT, Miyawaki T, Barakat K, DiNick V : Clinical outcome in cranioplasty : critical review in long-term followup. J Craniofac Surg 14: 144-153, 2003

25. Sarov M, Guichard JP, Chibarro S, Guettard E, Godin O, Yelnik A, et al. : Sinking skin flap syndrome and paradoxical herniation after hemicraniectomy for malignant hemispheric infarction. Stroke 41 : 560-562, 2010

26. Schiffer J, Gur R, Nisim U, Pollak L : Symptomatic patients after craniectomy. Surg Neurol 47 : 231-237, 1997

27. Segal DH, Oppenheim JS, Murovic JA : Neurological recovery after cranioplasty. Neurosurgery 34 : 729-731; discussion 731, 1994

28. Shoakazemi A, Flannery T, McConnell RS : Long-term outcome of subcutaneously preserved autologous cranioplasty. Neurosurgery 65 : 505510; discussion 510, 2009

29. Yadla S, Campbell PG, Chitale R, Maltenfort MG, Jabbour P, Sharan AD : Effect of early surgery, material, and method of flap preservation on cranioplasty infections : a systematic review. Neurosurgery 68 : 11241129; discussion 1130, 2011 